\title{
CURRÍCULO E AUTONOMIA NA ESCOLA PORTUGUESA: UMA ANÁLISE CRÍTICA DA CENTRALIZAÇÃO NOS ENSINOS BÁSICO E SECUNDÁRIO ${ }^{1}$
}

\author{
José Augusto Pacheco ${ }^{2}$ \\ Micaela Marques \\ Universidade do Minho
}

\section{RESUMO}

Pretende-se com este artigo focar as políticas educativas em Portugal, relativas aos ensinos básico e secundário, a partir da globalização e analisar de modo crítico as mudanças acontecidas na escola e no currículo. Constata-se que o movimento global da educação acentua a noção de escola como organização produtiva e contribui para formas de governação curricular centradas em testes, de acordo com procedimentos que são reforçados pela avaliação externa, incluindo a avaliação institucional e a avaliação das aprendizagens. Palavras-chave: políticas educativas em Portugal; ensinos básico e secundário

\section{CURRICULUM AND AUTONOMY AT SCHOOL PORTUGUESE: A CRITICAL ANALYSIS OF CENTRALIZATION IN PRIMARY AND SECONDARY EDUCATION}

\begin{abstract}
Posited in a globalization context, this article focuses on Portuguese educational politics regarding basic and secondary education, analyzing critically the changes that took place in school and in curriculum. It is observed that education's global movement not only stresses the idea of school as a productive organization, but also contributes to the consolidation of test-based curriculum governance, according to procedures reinforced by external evaluation, including institutional and learnings' evaluation.
\end{abstract}

Keywords: Educational policies in Portugal; primary and secondary education

\section{Introdução}

Falar de globalização educacional é reconhecer que os sistemas educativos estão confrontados com um movimento de uniformização, tornando-se as escolas não só mais responsabilizadas pelos resultados académicos dos alunos, como também menos autónomas, sobretudo no que diz respeito à autonomia curricular. Tendo como ponto de partida as políticas educativas, o texto inclui uma análise crítica da realidade das escolas dos ensinos básico (fundamental) e secundário (médio), em Portugal, afirmando-se que o movimento global da educação acentua a noção de escola como organização produtiva e contribui para formas de governação curricular centradas em testes, de acordo com procedimentos que são reforçados pela avaliação externa. 


\section{Globalização educacional}

São inúmeros os textos escritos, nas últimas décadas, sobre as diversas dimensões da globalização, incluindo as económicas, políticas e culturais (RITZER, 2007; SANTOS, 2008), bem como as que se prendem com a mentalidade dos sujeitos em contexto de novos espaços suprarregulados (LIPOVETSKY \& SERROY, 2010; LOMBARDI, 2003). De facto, a globalização é um processo enredado numa complexidade não só de discursos, que conduzem a políticas de partilha de conhecimento (STEINER-KHAMSI, 2012), mas também de processos orientados por novos modos de governação, com ênfase nos resultados (MAROY, 2012; AZEVEDO, 2007; TEODORO, 2003). Deste modo, são proclamadas palavras de elevado valor utilitário - por exemplo, qualidade, eficiência e prestação de contas - e, como diz, Horkheimer $(2014$, p. 95), "a preferência por palavras e frases simples, que podem ser agregadas de um só golpe, é uma das tendências anti-intelectuais, antihumanistas, manifestas no desenvolvimento da linguagem moderna, bem como da vida cultural em geral".

Sendo conhecido o método (conceitual) acerca do modo como a globalização trabalha na realidade social, ou seja, através de palavras-chave que adquirem uma centralidade ímpar em documentos de regulação transnacional (PACHECO, 2011), a educação e formação são duas áreas fortemente permeáveis a tais influências, com forte impacto nas conceções de escola e de currículo, sendo este último conceito entendido como um projeto de formação que ocorre em contextos fornais e/ou informais em função de um dado tempo e de um determinado contexto (Pacheco, 2014a), com uma matriz de construção bem complexa devido aos territórios contestados (TADEU DA SIVA \& MOREIRA, 1999) e às imensas leituras que se tornam possíveis na sua problematização teórica (LOPES \& MACEDO, 2011) e investigativa (PINAR, 2014; PARAÍSO, 2010).

Deste modo, a globalização educacional é ampla na sua diversidade temática, promovendo a valorização das vozes eivadas de modelos de custo-benefício, como na lógica de mercado, pois entender-se-á que a educação é um produto transacionável, sujeito às regras de oferta e procura, face às vozes que reclamam a contextualização e a singularidade do que acontece no interior das escolas e no modo como o currículo é trabalhado em cada escola pelos professores e alunos. Além disso, enraíza-se nos decisores políticos o movimento de reforma de educação global, direcionado para a estandardização, a prestação de contas externa e os testes à larga escala, como reconhecem Hargreaves e Fullan (2012).

\section{Mudanças políticas}

Com alguma autoridade documental, sobretudo a partir de relatórios de organismos transnacionais e supranacionais e de documentos de orientação política dos governos nacionais, poder-se-á argumentar que a globalização interseta a educação e a formação no modo como a escola é pensada como organização produtiva, na extensão da ideia de que a escola é um negócio, tutelada "de acordo com o modelo da linha de montagem fabril" (PINAR, 2007, p. 53), e na forma como o currículo é transformado num dispositivo de resultados, que joga a sua força social através de uma cultura de performatividade (MOREIRA, 2013a).

Tanto a escola e o currículo surgem, hoje em dia, no contexto de reformas viajantes (STEINER-KHAMSI, 2012) que afetam de igual modo os sistemas educativos nacionais, subjugados à estandardização e uniformização, mesmo que as ideias da descentralização e da flexibilização sejam as mais veiculadas nos discursos políticos, ignorando-se que, na linha 
de pensamento de Bernstein (1999), persista a recontextualização, pela força da avaliação externa, tanto a de natureza institucional (SOBRINHO, 2002; PACHECO, 2014B; PACHECO, MORGADO \& BORGES, 2014), quanto a que está relacionada com sistemas nacionais de avaliação das aprendizagens. Neste caso, reconhecer-se-á que os governos nacionais, e também instâncias transnacionais, investem elevados recursos financeiros na implementação de dispositivos de avaliação do desempenho escolar (SCHILDKAMP \& TEDDLIE, 2008), como é o caso paradigmático do teste PISA da OCDE (POPKEWITZ, 2013) e de modelos de avaliação centrados em resultados, originando o que Grinnel e Rabin (2013) designam por tragédia dos efeitos comuns, que faz da escola um lugar por excelência de procedimentos uniformes.

$\mathrm{Na}$ realidade portuguesa, a escola dos ensinos básico e secundário é centralizada, apesar de existir legislação, desde 1989, que proclama a sua autonomia, entretanto contratualizada, a partir de 2011, tornando-se o contrato entre o Ministério da Educação e as escolas numa estratégia coercitiva de cumprimento de metas estratégicas em termos de resultados académicos. Trata-se, com efeito, de uma autonomia construída na base da avaliação das aprendizagens dos alunos, ganhando mais credibilidade social as avaliações externas, decretadas para o ensino básico (nos anos finais de ciclo, isto é, nos $4^{\circ}, 6^{\circ}$ e $9^{\circ}$ anos de escolaridade) desde $2005^{3}$, e mantidas no ensino secundário, depois de terem sido retomadas em 1993.

Como reconhece Lima (2011), a escola portuguesa mantém-se centralizada nos seus mecanismos de decisão, mesmo que exista a tendência para que nos discursos políticos seja reiteradamente proclamada a sua autonomia. Ainda no seu entendimento, a autonomia contratualizada pressupõe o comportamento hierárquico e autoritário do Ministério da Educação, largamente reforçado, ao longo dos últimos anos, com o agrupamento de escolas, tendo gerado a formação de estruturas organizacionais mais amplas, essencialmente ditadas por critérios administrativos, e criado um novo escalão da administração centralizada. $\mathrm{O}$ agrupamento de escolas representa, acima de tudo, o reordenamento da oferta educativa, a racionalização de recursos e a competitividade.

Confrontando-se a realidade discursiva do normativo ${ }^{4}$, que institui a atual forma de governação das escolas, com as suas práticas de gestão/administração, constata-se que o propósito de valorização de uma cultura de autoavaliação e de avaliação externa, com a consequente introdução de mecanismos de autorregulação e melhoria dos desempenhos pedagógicos e organizacionais, como se lê no preâmbulo da lei, se torna proeminente nas opções dos últimos governos, remetendo-se a autonomia para os dispositivos de controlo que, em primeiro lugar, devem tornar-se numa prioridade para a própria escola.

Pode, assim, interpretar-se, com argumentos de análise crítica, que a escola portuguesa é supostamente autónoma na sua componente organizacional e que o seu modo de gestão e administração em nada contribui para a existência de uma autonomia curricular, mais ainda quando as políticas de descentralização não são senão uma forma concreta de autonomia decretada.

Mesmo que a ideia seja recorrente em discursos políticos de responsáveis governamentais, a escola portuguesa dos ensinos básico e secundário não é autónoma curricularmente. Jamais o foi no passado e dificilmente o será no futuro, dado que existe um consenso largamente partilhado de que a escola portuguesa é de âmbito nacional, aliás como está expresso na Lei de Bases do Sistema Educativo, representando as componentes regionais um mero adereço linguístico.

Esta é uma constatação que pode ser feita, com legitimidade histórica, desde a década de 1860, momento em que o currículo nacional se tornou realidade nas escolas portuguesas (PACHECO, 2006, 2003). Segundo Huebner (1975), o currículo nacional transforma-se 
numa poderosa linguagem de controlo e prescrição, ditando regras formais acerca do modo da sua organização na escola, bem como dos procedimentos, relativos a objetivos, conteúdos, atividades e avaliação, que estão na base do processo ensino/aprendizagem.

Esta arquitetura curricular tem raízes teóricas na obra de Tyler (1949), autor de um dos mais pequenos, mas preponderantes, livros alguma vez publicados em educação, e que viria a tornar-se no berço da pedagogia por objetivos, alterada, a partir da década de 2000, pela pedagogia por competências. A noção de competência ganhou forma no currículo nacional, em Portugal, no processo de revisão curricular de 2001, para o ensino básico ${ }^{5}$, propondo-se como fundamento da sua legitimação a ineficácia da escola (ROLDÃO, 2003) e o excessivo pendor cognitivo do conhecimento escolar. Se bem que entre objetivo e competência exista uma linha de continuidade em termos da sua formulação pedagógica (PACHECO, 2011), o currículo orientado para as competências foi apresentado como sendo flexível e construído pelos professores. Não pode existir argumento mais falacioso do que este, sobretudo se for entendida a competência como uma peça do dispositivo curricular, reorientando-o para saberes concretos e relacionais, razão porque uma das críticas feitas por Young (2010, p. 204) à utilização da competência em contexto escolar está relacionada com uma "visão excessivamente instrumental do conhecimento e da educação que envolvem", tornando-se numa peça-chave do taylorismo educacional (STOLLER, 2015).

Porém, com o fim legislativo da competência no currículo do ensino básico, ocorrido em 2011, e a instauração, depois de um processo embrionário de 2010 a 2012, de metas curriculares, tanto no básico como no secundário, entretanto generalizadas de 2012 a 2015, o conhecimento escolar pode ter perdido a instrumentalidade do saber-fazer, mas acentuou a sua natureza de ser suscetível de ser mensurável. Assim, a meta curricular, pela sua forma de apresentação do currículo, é um standard de conteúdos apresentados na forma de listas extensas de objetivos, com a função de regular o ensino e a aprendizagem, sobrepondo-se ao programa. Aliás, o currículo dos ensinos básico e secundário, considerando também o da educação pré-escolar (dos três aos seis anos), transformou-se numa montanha de normativos fragmentados, repetitivos e contraditórios, sendo uma tarefa hercúlea a sua definição e compreensão nos textos distribuídos por leis, decretos-lei, portarias, despachos e despachos normativos. Como noutros setores das decisões políticas, jamais se legislou tanto no campo da educação como nos últimos 25 anos, sobretudo no que diz respeito à organização escolar e ao currículo, com preponderância para novos programas, metas curriculares, avaliação externa (tanto institucional como de aprendizagens), reestruturação de planos curriculares, reorganização da rede escolar e avaliação de desempenho docente.

Ainda na sua organização, o currículo dos ensinos básico e secundário, especialmente o que foi definido pelas reformas educativas pós-Lei de Bases do Sistema Educativo ${ }^{6}$, isto é, entre 1986 e 2015, tem sido marcado pela ambiguidade política, com decisões que têm oscilado entre o currículo insular, detalhado pelas disciplinas, e o currículo relacional, de natureza sociocultural, mesmo que a tendência para o currículo das disciplinas seja o mais marcante nas aprendizagens escolares, fortemente reforçado nos últimos anos, sobretudo a partir do momento em que as aprendizagens a Português e Matemática são avaliadas externamente no ensino básico, observando-se que começa a ser implementado quer nos primeiros quatros anos de escolarização ( $1^{\circ}$ ciclo do ensino básico), quer na educação préescolar.

A noção de currículo expressa pela Comissão de Reforma do Sistema Educativo (CRSE, 1987, p. 185) - responsável pela primeira grande reforma educativa depois de 1974 e pela produção de um pensamento curricular - foi a de "um plano de ação, que define o quadro geral de desenvolvimento dos projetos educativos", tendo "um plano de ação, que define o quadro geral de desenvolvimento dos projetos educativos", embora tivesse 
reconhecido que "as condições de funcionamento das escolas não oferecem, regra geral, um suporte eficaz ao desenvolvimento curricular" (Ibid., p. 188).

Muitos dos aspetos enunciados pela CRSE $(1987,1988)$ mantiveram-se até aos dias de hoje, ainda que aspetos de melhoria substantiva tenham sido introduzidos nas escolas, particularmente ao nível de recursos e materiais didáticos e de apoios pedagógicos para os alunos. Porém, com a mudanças operadas a partir de 2012, por motivos que também se prendem com as políticas de austeridade financeira impostas pela troika (Fundo Monetário Internacional, Banco Central Europeu e União Europeia), com materialização de cortes orçamentais significativos na educação, o currículo perdeu as áreas curriculares não disciplinares (Área de Projeto, Estudo Acompanhado e Formação Cívica), passando a existir a oferta complementar, pretensamente o campo por excelência da autonomia da escola em termos curriculares, bem como as atividades de enriquecimento curricular, no $1^{\circ}$ ciclo do ensino básico, de natureza facultativa e lúdica, que se transformaram num verdadeiro tubo de ensaio da municipalização da educação, pois o Estado delegou nas autarquias a responsabilidade da sua organização.

Deste modo, a formação pessoal e social dos alunos é agora uma formação transdisciplinar, desenvolvida através de projetos orientados para a educação cívica, educação para a saúde, educação financeira, educação para os mídia, educação rodoviária, educação para o consumo e educação para o empreendedorismo, entre outras. Na história do sistema educativo português, a organização do currículo em formações transdisciplinares tem conhecido uma mesma resposta ao longo do tempo: não se realiza, porque sendo de todos os professores não é de ninguém. É pertinente, contudo, dizer que a inovação da Lei de Bases o Sistema Educativo esteve essencialmente em dois aspetos que jamais viriam a ter concretização: a área de formação pessoal e social (para os ensinos básico e secundário) e a introdução de componentes regionais no ensino básico e de componentes regionais e locais no ensino secundário, sem prejuízo do estabelecimento à escala nacional dos respetivos planos curriculares. Aliás, Lemos Pires (1996, p. 10), é bem elucidativo relativamente à área de formação pessoal e social:

No decorrer dos trabalhos demo-nos conta que faltaria algo inovador no domínio dos conteúdos de aprendizagem, que se usa ser tratado no currículo. O que estava inscrito já nos textos construídos mais não era do que as banalidades curriculares habituais, de lógica disciplinar a caminho da obsolescência. Mais não sabíamos fazer. Ocorreu-nos consultar alguém que nos parecesse capaz de criar uma "pedrada no charco" [...] da prestimosa e generosa contribuição, resultou o que consta dos números $1 \mathrm{e}$ 2 do art. $47^{\circ}$ da lei, a originar mais tarde toda a filosofia do desenvolvimento pessoal e social, e que hoje reputo ser o cerne de qualquer reforma educativa séria.

Nos anos mais recentes, os responsáveis pelas políticas educativas têm traçado a definição de um currículo nacional construído na base de três pilares essenciais para todas as escolas dos ensinos público e privado: a matriz dos planos curriculares; os programas com os conteúdos e orientações metodológicas; as metas curriculares com vista à mensuração das aprendizagens. Na sua definição legislativa, o currículo dos ensinos básico e secundário corresponde ao conjunto de conteúdos e objetivos, tendo como referência os programas das disciplinas e as metas curriculares homologados pelo Ministério da Educação ${ }^{7}$.

Esta é de facto a realidade curricular das escolas portuguesas, com autonomia declarada no enunciado retórico dos normativos nacionais e com um controlo das escolas e professores através de procedimentos de avaliação externa, perfilhando-se que o valor 
educacional de uma escola está na classificação dos resultados obtidos em provas (ensino básico) e exames (ensino secundário) nacionais.

Por outro lado, a identidade do professor é perspetivada como um gestor empresarial, assim definido por Hargreaves e Fullan (2015, p. XIII): "limita o currículo, volta-se para a tecnologia, prescreve e segmenta a instrução, ensina para os testes, reduz a literacia a pequenos trechos de compreensão em vez de envolvimentos mais significativos através de textos absorventes". Quer dizer, assim, que o professor será alguém mais preocupado com a implementação das políticas governamentais do que com as respostas que se torna necessário dar às diversas necessidades dos alunos. Constata-se, assim, que o currículo tem uma moldura política em constante mudança, mantendo linhas de continuidade ao nível dos seus processos e práticas de decisão, verificando-se que o Ministério da Educação, dos sucessivos governos, tem estado mais preocupado com os resultados académicos dos alunos e com uma educação orientada para o empreendedorismo e para aa utilização aleatória das novas tecnologias, do que com a sua formação humana, não existindo, hoje em dia, na maioria das escolas, suficientes recursos humanos especializados para responder às diversas necessidades dos alunos. Neste caso, e com as aprendizagens apressadas e voltadas essencialmente para os resultados numéricos, as escolas podem transformar-se mais em lugares de formatação de alunos do que verdadeiramente espaços de formação integral visível pela qualidade dos resultados académicos e sociais.

\section{Formas de governação do currículo}

As mudanças operadas pelas políticas educativas estão presentes na descrição de duas governamentalidades curriculares que constituem o roteiro das políticas educativas orientadas para a prestação de contas. Pacheco e Marques (2014, p. 108) sustentam que a abordagem centrada nos testes é essencialmente definida por uma abordagem curricular centrada em resultados e por uma abordagem centrada em standards, ou seja, "duas governamentalidades curriculares expressas nas práticas quotidianas curriculares, cada vez mais inseridas numa lógica empresarial para a educação, em normas concretas para a privatização das escolas, em dispositivos de avaliação externa e em práticas de mercadorização curricular".

Tais formas de governação curricular, que destacam, entre outros aspetos, o desempenho ao nível dos resultados, os testes à larga escala, com incidência nos testes transnacionais, de que o PISA é o padrão, o ranking de escolas e a linguagem das competências $^{8}$, uma outra forma de apresentar objetivos de aprendizagem e metas curriculares, originam não só uma escolarização restrita, que inclui o core curriculum e provoca o mimetismo curricular, como também a coerção avaliativa, em que a avaliação é marcada pela resultados entendidos como scores numa prática de competição. Deste modo, o perfilhamento destas formas de governamentalidade curricular confronta o professor com o que pode ser denominado recontextualização performativa, isto é, uma coerção avaliativa, quer ao nível da produção de discursos, quer no plano das práticas, que sobrepõe as questões técnicas às pedagógicas, nomeadamente, questões sobre a eficiência e eficácia do processo educacional" (BIESTA, 2013, p. 41).

Como se se tratasse de um pêndulo que oscila entre o transnacional e o nacional, a globalização define as políticas educativas através de conceitos-chave e impõe padrões para a sua implementação, não pelos processos, mas pelos resultados. Esta é, de facto, uma mudança substantiva com reflexos no modo de perspetivar a profissionalidade docente, 
como bem analisou Maria Teresa Estrela em muitos dos seus escritos (CAETANO, RODRIGUES \& ESTEVES, 2015).

De mão dada com a globalização anda a cultura de prestação de contas, que não para de crescer e que parece não ter fim, situando-se os professores "num movimento de pinça entre os pais e os burocratas" (HARGREAVES \& FULLAN, 2012, p. 35), pois as políticas são cada vez mais "iniciativas administrativas fragmentadas, incoerentes e passageiras" (Ibid., p. 36).

Deste modo, e recorrendo-se aos mesmos autores, o currículo é estandardizado e por vezes é prescrito em detalhes excruciantes, as escolas têm menos recursos, há turmas com mais alunos, há falta de tempo para o desenvolvimento profissional docente, exalta-se a importância dos testes, valoriza-se o ranking de escolas e as intervenções da inspeção escolar são mais pontuais, para além de cultivar-se uma colaboração formal, burocrática e baseada em procedimentos administrativos.

Que imagem prevalece de escola a partir destas duas governamentalidades curriculares?

Trata-se, com efeito, de uma escola focada quer nos resultados externos, numa aprendizagem definida pelas metas curriculares e numa avaliação marcada pelo ritmo periódico dos testes, quer por um conhecimento poderoso, no sentido que é definido por Young (2010) Marshall (2014) e Morgan (2014), ou seja, pelo conhecimento ligado às principais disciplinas.

$\mathrm{Na}$ realidade portuguesa, a escola do ensino básico tem como principais disciplinas, pelo menos com provas nacionais externas, o Português e a Matemática, sendo que o Inglês se assume cada vez mais como disciplina estruturante do plano curricular, não só porque já existe um teste diagnóstico externo obrigatório para os alunos do $9^{\circ}$ ano de escolaridade, que confere uma certificação extra de uma universidade estrangeira, como também foi introduzida como disciplina obrigatória a desde do $3^{\circ}$ ano de escolaridade a partir de setembro de 2015, depois de ter sido incluída, durante alguns anos, nas atividades de enriquecimento curricular do $1^{\circ}$ ciclo do ensino básico. Por sua vez, a escola do ensino secundário é quase totalmente marcada pelos exames nacionais, se bem que uns mais importantes do que outros, de acordo com a sua influência na classificação final do aluno, que é determinante na seriação dos alunos para a entrada no ensino superior público. A avaliação externa é, assim, marcante no processo de desenvolvimento do currículo, conferindo-lhe uma centralidade que invalida a existência de uma autonomia curricular das escolas, mesmo que a ideia de decisão curricular esteja implícita na referência ao papel dos professores como decisores curriculares, como reconhece Leite (2014), mas somente de forma implícita nos normativos legais.

A realidade fora das palavras dos normativos que regulam a escola e o currículo é totalmente diferente. Com efeito, como já referimos, instala-se nas escolas a pressão junto dos professores no sentido de prepararem os alunos para os testes padronizados (GUISBOND, NEILL \& SCHAEFFER, 2012), em disciplinas que se tornam definidoras de um core curriculum (caso do Português e da Matemática), reconhecendo-se-lhes uma limitada autonomia pedagógica em termos de avaliação. No caso concreto português, os resultados dos alunos na avaliação sumativa externa (exames nacionais) tornam-se em dados estatísticos para a elaboração de seriações pela mídia, sendo o tempo da sua divulgação um momento de glorificação da escola privada e de desvalorização da escola pública, como se as duas escolas tivessem os mesmos públicos escolares e a mesma realidade socioeconómica.

O trabalho para os rankings, consubstanciado no ensino para os testes, origina uma aprendizagem apressada, fazendo com que os professores se tornem em meros funcionários do ato pedagógico que acontece na sala de aula, reconhecendo Hargreaves e Fink (2007, p. 
68), que "vivemos em países com escolas apressadas", substituindo-se os programas por metas curriculares e enchendo-se o currículo com mais conteúdos aferrolhados num tempo passado. Neste contexto, os testes convertem-se em fatores de recentralização do currículo, condicionando a autonomia pedagógica dos professores e impondo, por vezes, uma memorização a curto prazo (TAUBMAN, 2009), na medida em que se cultiva na escola uma aprendizagem para o momento, facilmente esquecida depois da realização dos testes.

Para lá desta linguagem dos testes, instala-se na sociedade a crença de que a meritocracia melhora com a privatização, em que a escola pública (no currículo e no financiamento) é administrada privadamente, no sentido de garantir a escolha como princípio regulador do mercado. Mas os dados sugerem que a "manutenção destas políticas evidencia apenas a disposição ideológica de afirmar que o privado é melhor que o público" (FREITAS, 2012, p. 385).

Mais do que simples retórica, a proposta de mudança em curso, e com reflexos evidentes nas políticas educativas portuguesas, por exemplo, através da promoção de estratégias uniformes de literacias, as decisões curriculares e pedagógicas seguidas nas escolas pelos professores refletem práticas estandardizadas, impostas no sentido de uma regulação top-down, que condicionam a sua autonomia ao nível pedagógico. A título de exemplo e como já foi referido por Pacheco e Marques (2014), nos dias de hoje, os manuais escolares de matemática em vigor contêm, como propostas de exercícios, as questões que saíram em exames nacionais/provas finais de ciclo e testes intermédios de anos anteriores, além de proporem, com muita frequência, questões "tipo-exame". Pode dizer-se que os autores dos manuais seguem as indicações emitidas pelo então GAVE (Gabinete de Avaliação Educativa), através dos relatórios de avaliação dos resultados dos exames nacionais e testes intermédios. Por exemplo, no relatório dos testes intermédios de 2012, publicado em 2013, lê-se que "a resolução dos testes intermédios/exames nacionais já realizados e o cumprimento das propostas apresentadas pelos manuais adotados nas escolas continuarão a ser uma boa base de trabalho para a apropriação de rotinas e para o desenvolvimento das capacidades exigidas a um aluno do ensino básico" (GAVE, 2013, p.42). Também num relatório sobre os exames nacionais, publicado em 2010, o citado organismo refere que um dos aspetos que torna benéfica a avaliação externa das aprendizagens, do ponto de vista educacional, é o facto de o trabalho dos professores poder ser "balizado por referentes de âmbito nacional, podendo assim garantir-se uma maior homogeneidade na forma como é trabalhado o currículo prescrito" (GAVE, 2010, p. 3). Reconhecer-se-á, deste modo, que "os exames e os sistemas de avaliação [externos] funcionam como reguladores das práticas curriculares e das decisões pedagógicas das escolas" (HYPOLITO \& IVO, 2013, p. 382), acentuando ainda mais o currículo formal e prescrito.

\section{Conclusão}

A análise da realidade curricular da escola portuguesa dos ensinos básico e secundário, incluindo de igual modo a educação pré-escolar, revela que nem sempre as políticas educativas têm sido claras no sentido da promoção da autonomia curricular da escola, mesmo que os normativos sejam exuberantes na ideia de que a escola é descentralizada, dispondo de autonomia para flexibilizar e contextualizar o currículo através do seu projeto educativo e dos seus planos de turma. Face a políticas transnacionais indutoras de práticas de prestação de contas, a implementação do currículo em escolas sem autonomia efetiva tem seguido, nos últimos anos, uma abordagem centrada em testes, essencialmente definida pela 
abordagem centrada em resultados e pela abordagem centrada em standards, de que as metas curriculares são a pretensa inovação curricular para a valorização do conhecimento escolar. Baseando-se na realidade brasileira, e assumindo uma posição de síntese entre a revalorização do conhecimento escolar e a consideração das escolas como espaços de crítica cultural, Moreira (2013a, p. 192) assume:

\begin{abstract}
A escola precisa constituir-se em espaço de crítica cultural, de pesquisa e de atuação formativa para o trabalho. Precisa estar atenta às rápidas mudanças que ocorrem na sociedade contemporânea. Precisa estar atenta aos desenvolvimentos tecnológicos que marcam nossa época. Contudo, precisa analisar, a persistência na sociedade, da desigualdade e da opressão. Precisa renovar-se. Precisa expressar propósitos de inovação que não se restrinjam à modernização, à supervalorização das novas tecnologias, à adesão impensada ao novo, à aparência, ao acessório, a mudanças simplesmente epidérmicas. Não custa insistir que não haverá inovação sem a modificação do pensamento, das crenças, dos hábitos e das atitudes dos professores. Mas isso implica respeitar e valorizar devidamente esses profissionais.
\end{abstract}

Tal imagem, explorada pelo autor noutros textos (Moreira, 2103b, 2013c), sobre a escola reforça a necessidade de olhar criticamente para as políticas educativas, questionando-se de que forma estão a contribuir para a existência de uma escola centralizada, sem autonomia curricular e com dispositivos centrados em resultados que, hoje em dia, pretendem traduzir a qualidade das aprendizagens.

\title{
Referências (norma APA)
}

Azevedo, Joaquim (2007). Sistema educativo mundial. Ensaio sobre a regulação transnacional da educação. V.N. Gaia: Fundação Manuel Leão.

Bernstein, Basil (1999). Vertical and horizontal discourse. British Journal of Sociology of Education, 20 (2), 157-173.

Biesta, Gert (2013). Para além da aprendizagem. Educação democrática para um futuro humano. Belo Horizonte: Autêntica.

Caetano, Ana Paula, Rodrigues, Ângela, \& Esteves, Manuela (2015). As ciências da educação na obra de Maria Teresa Estrela. Lisboa: Educa.

CRSE (1997). Documentos Preparatórios. Lisboa: Ministério da Educação, Vol. I.

CRSE (1988). Proposta global de reforma. Relatório final. Lisboa: Ministério da Educação.

Freitas, Luís C. (2012). Os reformadores empresariais da educação: da desmoralização do magistério à destruição do sistema público de educação. Educação \& Sociedade, 33 (119), 379-404.

GAVE (2010). Relatório - Um olhar sobre os exames nacionais. Lisboa: Ministério da Educação. Acedido novembro, 24, 2013, em http://www.gave.minedu.pt/np3content $/$ ?newsId=24\&fileName=Report_2009.pdf

GAVE (2013). Projeto Testes Intermédios - Relatório 2012. Lisboa: Ministério da Educação e Ciência. Acedido novembro, 24, 2013, em http://www.gave.minedu.pt/np3content/?newsId=24\&fileName=Relatorio_TI_2012.pdf

Grinnel, Smith, \& Rabin, Colette (2013). Modern education: a tragedy of the commons. Journal of Curriculum Studies, 45 (6), 748-767. 
Guisbond, Lisa, Neill, Monty, \& Schaeffer, Bob (2012). A década de progresso educativo perdida sobre a NCLB: que lições tirar deste fracasso político? Educação \& Sociedade, 33 (119), 405-430.

Hargreaves, Andy \& Fullan, Michael (2012). Professional capital. Transforming teaching every school. London: Routledge.

Hargreaves, Andy , \& Fink, Dean. (2007). Liderança sustentável. Porto: Porto Editora.

Horkheimer, Max (2015[1944]). O eclipse da razão. Lisboa: Antígona.

Huebner, Dwayne (1975). The tasks of the curricular theorist. In W. Pinar(Ed.), Curriculum theorizing. The reconceptualist (pp. 250-270). Berkeley: McCuctchan Publihing Company.

Hypolito, Álvaro, \& Ivo Andresa (2013). Políticas curriculares e sistemas de avaliação. Efeitos sobre o currículo. Revista E-Curriculum, 11, 376-392.

Leite, Carlinda (2014). Projeto contextualizar o saber para a melhoria dos resultados dos alunos (Policopiado). Porto: Universidade do Porto.

Lemos Pires, Eurico (1996). Memória da construção de uma lei. Jornal Rumos, nº 12, pp. 10-11.

Lima, Licínio (2011). Administração escolar: estudos. Porto: Porto Editora.

Lipovetsky, Gilles, \& Serroy, Jean (2010). A cultura-mundo. Resposta a uma sociedade desorientada. Lisboa: Edições 70.

Lombardi, José C. (2003). Globalização, pós-modernidade e educação (2 ${ }^{a}$ ed). Campinas: Autores Associados.

Lopes, Alice C., \& Macedo (2011). Teorias do currículo. São Paulo: Cortez Editora.

Maroy, Christian (2012). Towards post-bureaucratic modes of governance. In: G. SteinerKhamsi; F. Waldow (Eds.), World yearbook of education 2012. Policy borrowing and lending in education (pp. 62-93). London: Routledge.

Marshall, Toby (2014). New teachers need acess to powerfull educational knowledge. British Journal of Educational Studies, 62 (3), 265-279.

Morgan, John (2014). Michael Young and the politics of the school curriculum. British Journal of Educational Studies, 63 (1), 1-18.

Nillbergh, Ilmi (2015). The problem of "competence" and alternatives from the Sandinavian perpectives of Bildung. Journal of Curriculum Studies, 47 (3), 334-354.

Pacheco, José A. (2003). Políticas curriculares. Referenciais para análise. São Paulo: Cortez Editora.

Pacheco, José A. (2006). Currículo: teoria e práxis (3a ed.). Porto: Porto Editora.

Pacheco, José A. (2011). Discursos e lugares das competências em contextos de educação e formação. Porto: Porto Editora.

Pacheco, José A. (2014a). Educação, formação e conhecimento. Porto: porto Editora.

Pacheco, José A. (2014b). Políticas de avaliação e qualidade da educação. Uma análise crítica no contexto da avaliação externa de escolas, em Portugal. Avaliação: Revista da Avaliação da Educação Superior, 19 (92), 363-371 [http://dx.doi.org/10.1590/S141440772014000200005].

Pacheco, José A. (Org.). (2014). Avaliação externa de escolas: quadro teórico-conceptual. Porto: Porto Editora.

Pacheco, José A., \& Marques, Micaela (2014). Governamentalidade curricular: ação dos professores em contextos de avaliação externa (pp. 105-135). In M. R. Oliveira (Org.), Professor: formação, saberes e problemas (pp. 105-135). Porto: Porto Editora.

Paraíso, Marlucy A. (2010). Pesquisas sobre currículos e culturas. Curitiba: Editora CRV. Pinar, W. (2007). O que é a teoria do currículo? Porto: Porto Editora. 
Pinar, William (Org). (2014). International handbook of curriculum research (2 ${ }^{a}$ ed.). New York: Routledge.

Popkewitz, Thomas (2013). PISA: números, conduta de normalização e a alquimias das disciplinas escolares. In A. Favacho, Pacheco, J. A. \& S. Sales (Org.), Currículo, conhecimento e avaliação: divergências e tensões (pp. 89-108). Curitiba: Editora CRV.

Ritzer, George (2007). The globalization of nothing 2. London: Sage Publications.

Roldão, Maria do Céu (2003). Gestão do currículo e avaliação de competências. Lisboa: Editorial Presença.

Santos, Milton (2008). Por uma outra globalização. Do pensamento único à consciência universal. Rio de Janeiro: Editora Record.

Schildkamp, Kim, \& Teddlie, Charles (2008). School performance feedback systems in the USA and in the Netherlands: a comparison. Educational Research and Evaluation, 14 (3), 255-282.

Steiner-Khamsi, Gita (2012). Understanding policy borrowing and lending. Building comparative policy studies. In G. Steiner-Khamsi \& F. Waldow (Eds.), World yearbook of education 2012. Policy borrowing and lending in education (pp. 5-17). London: Routledge.

Stoller, Aaron (2015). Taylorism and the logic of learning outcomes. Journal of Curriculum Studies, 47 (3), 317-333.

Tadeu da Silva, Tomaz \& Moreira, António F. (1999). Territórios contestados. O currículo e os novos mapas políticos e culturais ( $3^{a}$ ed.). Petrópolis: Editora Vozes.

Taubman, Peter (2009). Teaching by numbers. Deconstructing the discourse of standards and accountability in education. London: Routledge.

Teodoro, António (2003). Globalização e educação. Políticas educacionais e novos modos de governação. Porto: Edições Afrontamento.

Tyler, Ralph (1949). Basic principles of curriculum and instruction. Chicago: University of Chicago Press.

Willbergh, Ilmi (2015). The problems of competence and alternatives from de Scandinavian perspective of bildung. Journal of Curriculum Studies, 47 (3), 334-354.

Young, Michael F. (2010). Conhecimento e currículo. Porto: Porto Editora.

\section{Referências (norma brasileira)}

AZEVEDO, Joaquim. Sistema educativo mundial. Ensaio sobre a regulação transnacional da educação. V.N. Gaia: Fundação Manuel Leão, 2007.

BERNSTEIN, Basil. Vertical and horizontal discourse. British Journal of Sociology of Education, 20 (2), 157-173, 1999.

BIESTA, Gert. Para além da aprendizagem. Educação democrática para um futuro humano. Belo Horizonte: Autêntica, 2013.

CAETANO, Ana Paula, RODRIGUES, Ângela; ESTEVES, Manuela. As ciências da educação na obra de Maria Teresa Estrela. Lisboa: Educa, 2015.

CRSE. Documentos Preparatórios. Lisboa: Ministério da Educação, Vol. I, 1997.

CRSE. Proposta global de reforma. Relatório final. Lisboa: Ministério da Educação, 1998.

FREITAS, Luís C. Os reformadores empresariais da educação: da desmoralização do magistério à destruição do sistema público de educação. Educação \& Sociedade, 33 (119), p. 379-404, 2012. 
GAVE. Relatório - Um olhar sobre os exames nacionais. Lisboa: Ministério da Educação, 2010. Acedido novembro, 24, 2013, em http://www.gave.minedu.pt/np3content/?newsId=24\&fileName=Report_2009.pdf

GAVE . Projeto Testes Intermédios - Relatório 2012. Lisboa: Ministério da Educação e Ciência, 2013. Acedido novembro, 24, 2013, em http://www.gave.minedu.pt/np3content/?newsId=24\&fileName=Relatorio_TI_2012.pdf

GRINNEL, Smith; RABIN, Colette. Modern education: a tragedy of the commons. Journal of Curriculum Studies, 45 (6), p. 748-767, 2013.

GUISBOND, Lisa, NEILL, Monty; SCHAEFFER, Bob. A década de progresso educativo perdida sobre a NCLB: que lições tirar deste fracasso político? Educação \& Sociedade, 33 (119), p. 405-430, p. 2012.

HARGREAVES, Andy; FULLAN, Michael. Professional capital. Transforming teaching every school. London: Routledge, p. 2012-

HARGREAVES, Andy; FINK, Dean. Liderança sustentável. Porto: Porto Editora, 2007

HORKHEIMER, Max O eclipse da razão. Lisboa: Antígona, 2015[1944].

HUEBNER, Dwayne. The tasks of the curricular theorist. In W. Pinar (Ed.), Curriculum theorizing. The reconceptualist (p. 250-270). Berkeley: McCuctchan Publihing Company, 1975.

HYPOLITO, Álvaro; IVO, Andresa. Políticas curriculares e sistemas de avaliação. Efeitos sobre o currículo. Revista E-Curriculum, 11, p. 376-392, 2013.

LEITE, Carlinda. Projeto contextualizar o saber para a melhoria dos resultados dos alunos (Policopiado). Porto: Universidade do Porto, 2014

LIMA, Licínio. Administração escolar: estudos. Porto: Porto Editora, 2011.

LEMOS PIRES, Eurico. Memória da construção de uma lei. Jornal Rumos, nº 12, p. 10-11, 1996.

LIPOVETSKY, Gilles; SERROY, Jean. A cultura-mundo. Resposta a uma sociedade desorientada. Lisboa: Edições 70, 2010.

LOMBARDI, José C. Globalização, pós-modernidade e educação ( $2^{a}$ ed). Campinas: Autores Associados, 2003.

LOPES, Alice C.; MACEDO. Teorias do currículo. São Paulo: Cortez Editora, 2011.

MAROY, Christian. Towards post-bureaucratic modes of governance. IN: G. STEINERKHAMSI; F. WALDOW (Eds.), World yearbook of education 2012. Policy borrowing and lending in education (p. 62-93). London: Routledge, 2012.

MARSHALL, Toby. New teachers need acess to powerfull educational knowledge. British Journal of Educational Studies, 62 (3), p.265-279, 2014

MORGAN, John. Michael Young and the politics of the school curriculum. British Journal of Educational Studies, 63 (1), p. 1-18, 2014.

NILLBERGH, Ilmi. The problema of competence and alternatives from the Sandinavian perpectives of Bildung. Journal of Curriculum Studies, 47 (3), p. 334-354, 2015.

PACHECO, José A. Políticas curriculares. Referenciais para análise. São Paulo: Cortez Editora, 2003.

PACHECO, José A.. Currículo: teoria e práxis ( $3^{a}$ ed.). Porto: Porto Editora, 2006.

PACHECO, José A. Discursos e lugares das competências em contextos de educação e formação. Porto: Porto Editora, 2011.

PACHECO, José A. Educação, formação e conhecimento. Porto: porto Editora, 2014a.

PACHECO, José A. Políticas de avaliação e qualidade da educação. Uma análise crítica no contexto da avaliação externa de escolas, em Portugal. Avaliação: Revista da Avaliação da Educação Superior, 19 (92), p. 363-371 [http://dx.doi.org/10.1590/S141440772014000200005], 2014b. 
PACHECO, José A. (Org.). Avaliação externa de escolas: quadro teórico-conceptual. Porto: Porto Editora, 2014.

PACHECO, José A. ; MARQUES, Micaela. Governamentalidade curricular: ação dos professores em contextos de avaliação externa. IN: M. R. Oliveira (Org.), Professor: formação, saberes e problemas (p. 105-135). Porto: Porto Editora, 2014.

PARAÍSO, Marlucy A. Pesquisas sobre currículos e culturas. Curitiba: Editora CRV., 2010. PINAR, W. O que é a teoria do currículo? Porto: Porto Editora, 2007.

PINAR, William (Org). International handbook of curriculum research $\left(2^{a}\right.$ ed.). New York: Routledge, 2014.

POPKEWITZ, Thomas. PISA: números, conduta de normalização e a alquimias das disciplinas escolares. IN: A. FAVACHO; J. A. PACHECO; S. SALES (Org.), Currículo, conhecimento e avaliação: divergências e tensões (p. 89-108). Curitiba: Editora CRV, 2014.

RITZER, George. The globalization of nothing 2. London: Sage Publications, 2007.

ROLDÃO, Maria do Céu. Gestão do currículo e avaliação de competências. Lisboa: Editorial Presença, 2003.

SANTOS, Milton. Por uma outra globalização. Do pensamento único à consciência universal. Rio de Janeiro: Editora Record, 2008.

SCHILDKAMP, Kim; TEDDLIE, Charles- School performance feedback systems in the USA and in the Netherlands: a comparison. Educational Research and Evaluation, 14 (3), p. 255-282, 2008

STEINER-KHAMSI, Gita. Understanding policy borrowing and lending. Building comparative policy studies. IN: G. STEINER-KHAMSI; F. WALDOW (Eds.), World yearbook of education 2012. Policy borrowing and lending in education (p. 5-17). London: Routledge, 2012.

STOLLER, Aaron (2015). Taylorism and the logic of learning outcomes. Journal of Curriculum Studies, 47 (3), p. 317-333, 2015.

TADEU DA SILVA, Tomaz; MOREIRA, António F. Territórios contestados. O currículo e os novos mapas políticos e culturais ( $3^{a}$ ed.). Petrópolis: Editora Vozes, 1999.

TAUBMAN, Peter. Teaching by numbers. Deconstructing the discourse of standards and accountability in education. London: Routledge, 2009.

TEODORO, António. Globalização e educação. Políticas educacionais e novos modos de governação. Porto: Edições Afrontamento, 2003.

TYLER, Ralph. Basic principles of curriculum and instruction. Chicago: University of Chicago Press, 1949.

WILLBERGH, Ilmi. The problems of competence and alternatives from de Scandinavian perspective of bildung. Journal of Curriculum Studies, 47 (3), 334-354, 2015

YOUNG, Michael F. Conhecimento e currículo. Porto: Porto Editora, 2010.

\footnotetext{
${ }^{1}$ Este trabalho é financiado por Fundos FEDER através do Programa Operacional Fatores de Competitividade - COMPETE e por Fundos Nacionais através da FCT - Fundação para a Ciência e a Tecnologia no âmbito do projeto PTDC/CPE-CED/116674/2010.

${ }^{2}$ A correspondência acerca deste artigo deve ser feita para este email: jpacheco@ie.uminho.pt

${ }^{3}$ O Decreto-lei n.209/2002, introduziu os exames nacionais no final do 9. ${ }^{\circ}$ ano, a Português e a Matemática, tendo sido posteriormente regulamentados em 2005, pelo Despacho normativo n.1/2005. Em 2011, o Decretolei n.94/2011 a avaliação externa das aprendizagens em Português e Matemática foi alargada ao $6 .^{\circ}$ ano e em 2012, o Decreto-lei n.139/2012 definiu a realização de provas finais às mesmas disciplinas no final do $4 .^{\circ}$ ano.
} 
${ }^{4}$ Cf. Decreto-lei n. 75/2008, de 22 de abril, com alterações pelo Decreto-lei n. 137/2012, de 2 de julho.

${ }^{5}$ A revisão curricular do ensino secundário aconteceu em 2004, mas jamais a linguagem das competências foi utilizada neste nível de ensino.

${ }^{6}$ cf. Lei 14/86, de 14 de Outubro [Lei de Bases do Sistema Educativo].

${ }^{7}$ Cf. Decreto-lei n. 139/2012, de 5 de julho, alterado pelo Decreto-lei n. 91/2013, de 10 de julho.

${ }^{8}$ Sobre os discursos e linguagens de competência, cf. José Augusto Pacheco, 2011. Numa crítica à linguagem das competências, Ilmi Nillbergh, 2015, sustenta que a competência deve ser abandonada como conceito educacional, repondo-se a noção de bildung.

Recebido: mai/15 Aprovado: jun/15 